Hooshmand, H., Martinez, A. J., and Rosenblum, W. I. (1971) Arthrogryposis multiplex congenita: simultaneous involvement of peripheral nerve and skeletal muscle. Archives of Neurology, 24 , 561-572.

Kanof, A., Aronson, S. M., and Volk, B. W. (1956). Arthrogryposis: A clinical and pathological study of three cases. Pediatrics, 17, 532-540.

Lebenthal, E., Shochet, S. B., Adam, A., Seelenfreund, M., Fried, A., Najenson, T., Sandbank, U., and Matoth, Y. (1970). Arthrogryposis multiplex congenita: twenty three cases in an Arab kindred. Pediatrics, 46, 891-899.

Pearson, C. M. and Fowler, W. G., Jr. (1963). Hereditary nonprogressive muscular dystrophy inducing arthrogryposis syndroms. Brain, 86, 75-88.

Peña, C. E., Miller, F., Budzilovich, G. N., and Feigin, I. (1968). Arthrogryposis multiplex congenita: report of two cases of a radicular type with familial incidence. Neurology, 18, 926-930.

Srivastava, R. N. (1968). Arthrogryposis multiplex congenita: case report of two siblings. Clinical Pediatrics, 7, 691-694.

Swinyard, C. A. (1960). Progressive muscular dystrophy and atrophy and related conditions. Diagnosis and management. Pediatric Clinics of North America, 7, 703-732.

\section{A Case of Meningomyelocele in a Kindred with Multiple Cases of Spondylolisthesis and Spina Bifida Occulta*}

\author{
Summary. A child with meningo- \\ myelocele, and other spinal anomalies, \\ was born to a woman with three sibs who \\ had spondylolisthesis and whose father \\ and two of his sibs had a history of back \\ problems. The suggestion is made that \\ these anomalies represent a pattern of \\ autosomal dominant inheritance with \\ variable expressivity.
}

In an epidemiological study of spina bifida cystica a proposita with a strong maternal family history of spondylolisthesis was identified. Although spina bifida occulta is commonly found associated with spondylolisthesis, this family is of interest because of the presence of a case of meningomyelocele (the proposita) in a family with a marked occurrence of spondylolisthesis and spina bifida occulta.

\section{Case Reports}

The Proposita (IV.1) was admitted to The Children's Orthopedic Hospital and Medical Center in 1972, at the

Received 30 July 1973.

* This work was supported in part by NIH grant GM 15253. age of 2 days, for evaluation and treatment of an epithelialized $2 \times 4 \mathrm{~cm}$ cystic mass at T-4. The child was the product of a normal pregnancy and delivery to a 19-year-old, para 0 , white female. Radiology and myelography showed: (1) hemivertebrae of T-10 and also $\mathrm{T}-3$ through $\mathrm{T}-6$ or $\mathrm{T}-7 ;$ (2) deformed ribs; and (3) diastematomyelia at $\mathrm{L}-1$. The cystic mass was found at surgery to be a T-4 meningomyelocele. When the mother was later contacted as part of an epidemiological study of spina bifida cystica she informed us that three of her older sibs had been treated at University Hospital for a 'back defect'. These charts were reviewed and an additional sib found who had been evaluated for low back pain at the University Hospital. There was no family history of spina bifida cystica, anencephalus, or hydrocephalus.

K.T. (III.1) was seen in 1969 at University Hospital at age 22. She had had an onset of inconstant low back pain 2 years previously which had recurred. Radiological examination showed a bilateral defect in the pars interarticularis of L-5 with grade II spondylolisthesis at L5-S1. In addition spina bifida occulta of L-5 was demonstrated. She was treated by L-5 laminectomy and L5-S1 discectomy.

R.L.S. (III.2) was seen at University Hospital in 1968 at age 20 with a history of low back pain for many years. Upon $x$-ray examination the patient was found to have spondylolysis with anterior displacement of L-5 under L-4 (reverse spondylolisthesis), bilateral defects of the pars interarticularis, and slight spina bifida occulta of L-5. Treatment consisted of L-5 hemilaminectomy (rt) and L5-S1 and L4-5 discectomy.

J.L.S. (III.3) was seen at University Hospital, also in 1968 , at age 19 years, with a history of recurrent low back pain during the preceding 5 to 6 years. A myelogram revealed multiple anomalies of the L5-S1 area including bilateral defects in the pars interarticularis of L-5, grade I spondylolisthesis of L5-S1, and spina bifida occulta of S-1. The patient was treated by L-5 laminectomy with L5-S1 discectomy.

D.S. (III.4) was seen in 1968 at University Hospital at age 17. He had a history of intermittent low back pain with onset at age 14. Radiology showed sacral erosion of the anterior portion of the spinal canal approximately $3 \mathrm{~cm}$ in size. Spina bifida occulta of L-5 was present while spondylolisthesis was not. A myelogram showed blunting of L-5 and S-1 nerve roots on the left. No treatment was carried out.

Family History. From the histories of patients K.T., R.L.S., J.L.S., and D.S. it was learned that there was a history of back problems in generation II of this family. Their father (II.6) had had back trouble since age 17. Two of his sibs (II.3 and II.4) also had histories of back problems. Thus, it appears that there is a 


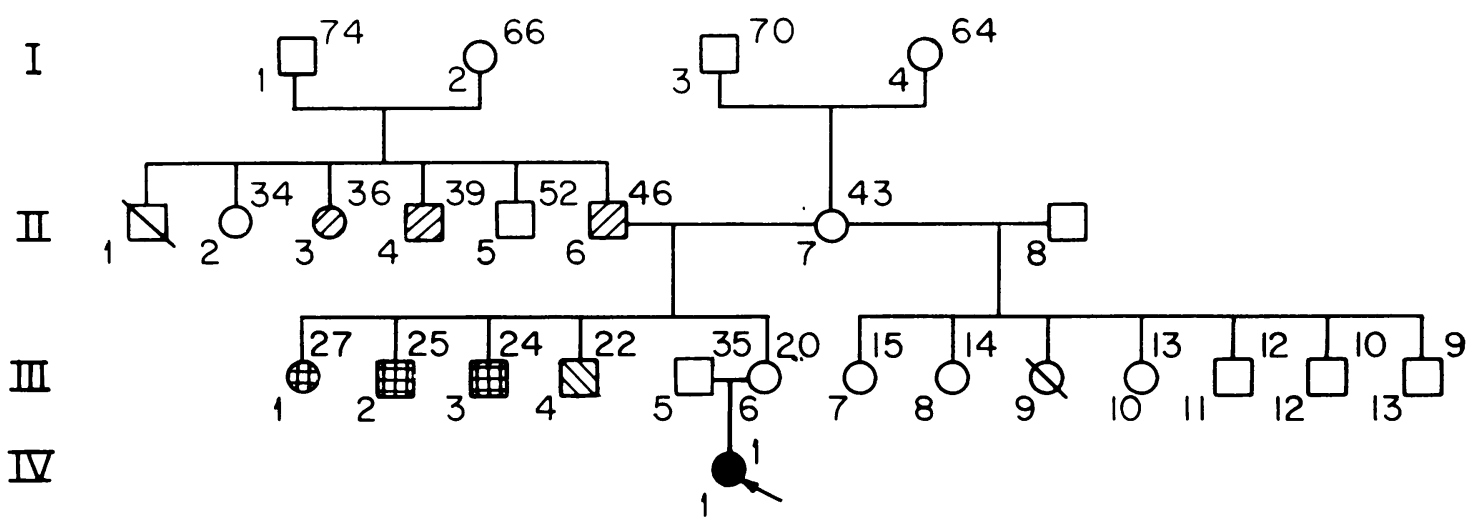

$\begin{array}{ccl}\text { MALE } & \text { FEMALE } \\ \square & \bigcirc & \begin{array}{l}\text { Normal } \\ \text { Died at birth } \\ \text { Spondylolisthesis } \\ \text { with Spina Bifida } \\ \text { Occulta } \\ \text { Spina Bifida Occulta } \\ \square\end{array} \\ \square & \bigotimes & \begin{array}{l}\text { History of back } \\ \text { problems }\end{array}\end{array}$

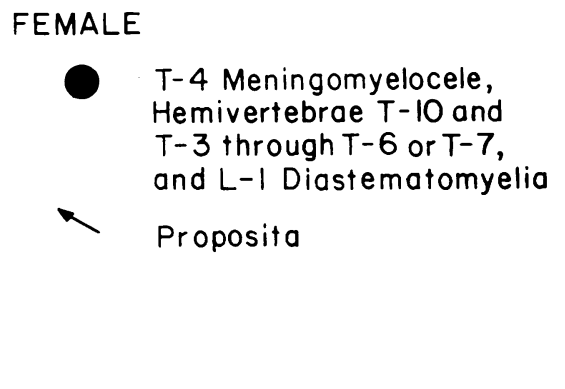

Frg. 1. Pedigree of the kindred with multiple occurrences of spondylolisthesis, spina bifida occulta, history of back problems, and a case of meningomyelocele.

history of possible vertebral defects through three generations of this family.

\section{Discussion}

The aetiologies of spina bifida cystica and spondylolisthesis remain unknown, although a genetic component is probably present in both. That spina bifida cystica is not a simple genetic defect appears clear from studies of twin discordance (Yen and MacMahon, 1968). Although Lorber (1965) has suggested recessive inheritance, the genetic basis of the defect is more often considered to be polygenic (Carter, 1969). Both dominant (Amuso and Mankin, 1967) and recessive (Wiltse, 1962) inheritance have been suggested for spondylolisthesis although important non-genetic factors are again involved. Pembrey (1972) presented a pair of identical twins discordant for spondylolisthesis. Probably the usual genetic basis for the defect is as an autosomal recessive with partial penetrance.

Spina bifida cystica is thought to be the result of failure of closure of the neural tube early in embryo- genesis, between approximately 22 and 28 days (Smith, 1970). Wiltse (1962) suggested that spondylolisthesis is due to a defect or dysplasia in the cartilage model of the arch of the affected vertebra and usually present in other vertebrae. This would be later in development than the failure of the neural tube to close which results in spina bifida cystica, although Pembrey (1972) referred to spondylolisthesis as a neural tube defect.

Newman (1963) has separated spondylolisthesis into five aetiological groups: group I (congenital); group II (spondylolytic); group III (traumatic); group IV (degenerative); and group V (pathological). Viewing our cases in this frame of reference, they appear to fall into group II since defects of the pars interarticularis, which are characteristic of this group, were present. The superior sacral facets were considered to be normal, abnormal sacral facets being characteristic of group I. If our cases are correctly assigned to Newman's group II, we suggest that there may be a congenital component in the development of group II, as well as in group I spondylolisthesis. 
To our knowledge no kindreds have been presented in the literature showing a case of spina bifida cystica in a family with multiple cases of spondylolisthesis. A marked association has been shown between spondylolisthesis and spina bifida occulta, since spina bifida occulta is five to 10 times more common in individuals with spondylolisthesis than in the general population (Pembrey, 1972). In the family presented by Amuso and Mankin (1967) five of the six surviving members of three generations had spondylolisthesis and spina bifida occulta.

The pattern in the family presented here is suggestive of autosomal dominant inheritance with variable expressivity. Given proper environmental conditions the genotype manifests itself phenotypically in spondylolisthesis with spina bifida occulta, the spondylolisthesis occurring during or after childhood with the spina bifida occulta developing embryonically. We suggest that the mother of the proposita carried this abnormal allele, although it was not expressed, and passed it to the proposita. Perhaps this allele, in conjunction with other aspects of the genotype and the intrauterine environment, led to the development of the multiple spinal anomalies of the proposita.

I would like to acknowledge the co-operation of The Children's Orthopedic Hospital and Medical Center in our study of the epidemiology of spina bifida cystica. Some of the data presented in this paper were obtained from consultation reports of the Division of Medical Genetics, Department of Medicine, University of Washington School of Medicine.

LOWELL E. SEVER Department of Epidemiology and International Health SC-36 and Center for Inherited Diseases University of Washington Seattle, Washington 98195, USA

REFERENCES

Amuso, S. J. and Mankin, H. J. (1967). Hereditary spondylolisthesis and spina bifida. Fournal of Bone and Foint Surgery, 49A, 507-513.

Carter, C. O. (1969). Spina bifida and anencephaly: a problem in genetic-environmental interaction. Fournal of Biosocial Science, 1, 71-83.

Lorber, J. (1965). The family history of spina bifida cystica. Pediatrics, 35, 589-595.

Newman, P. H. (1963). The etiology of spondylolisthesis. Fournal of Bone and foint Surgery, 45B, 39-59.

Pembrey, M. E. (1972). Discordant identical twins. V. Neural tube defects. The Practitioner, 209, 709-712.

Smith, D. W. (1970). Recognizable Patterns of Human Malformation: Genetic, Embryologic, and Clinical Aspects. Saunders, Philadelphia.

Wiltse, L. L. (1962). The etiology of spondylolisthesis. Fournal of Bone and foint Surgery, 44A, 539-560.

Yen, S. and MacMahon, B. (1968). Genetics of anencephaly and spina bifida? Lancet, 2, 623-626.

\section{Double Autosomal Trisomy and Mosaicism for Chromosomes No. 8 and No. 21*}

Summary. This patient was found to have a previously unreported double trisomy for chromosomes No. 8 and No. 21. She was recognized to have Down's syndrome at birth, and her subsequent development was consistent with that diagnosis. Her general health was good and there were no features suggesting an additional chromosomal abnormality. At this time there is no clearly recognized phenotype associated with trisomy 8 .

Two non-disjunctional events, occurring in meiosis and/or post-zygotic mitosis, are possible explanations of the chromosomal abnormalities found in this patient.

Double autosomal trisomy is rarely found in viable individuals, in contrast to the more frequently occurring autosomal trisomy with sex chromosomal aneuploidy. Most of the instances of double trisomy or trisomy with sex chromosomal aneuploidy have been observed in Down's syndrome. To our knowledge, double autosomal trisomy for a $\mathrm{G}$ chromosome and another autosome (either a D or an $\mathrm{E}$ chromosome) has been described in 11 liveborn children (Gagnon et al, 1961; Gustavson et al, 1962; Becker, Burke and Albert, 1963; Hsu et al, 1965; Smith, Tips, and Howard, 1965/1966; Tolksdorf, et al, 1965; Koch, Santamouris, and Ulbrich, 1967; Marks, Wiggins, and Spector, 1967; Zellweger and Abbo, 1967; Glogowska, 1969; Porter, Petersen, and Brown, 1969).

The child described here was found to have double trisomy and mosaicism for chromosomes No. 8 and No. 21, identified by Giemsa-banding patterns. The karyotype was $47, \mathrm{XX},+21 / 48, \mathrm{XX},+8$, +21 . At birth the phenotype was readily recognized as Down's syndrome, and there were no unusual features suggesting an additional chromosome abnormality. This is the first reported liveborn child with double autosomal trisomy involving chromosomes No. 8 and No. 21.

Received 24 August 1973.

* This study was supported in part by Grants No. 286 and No. 422 from the Maternal and Child Health Services, United States Public Health Service. 